\title{
Impact of poor disease surveillance system on COVID-19 response in africa: Time to rethink and rebuilt
}

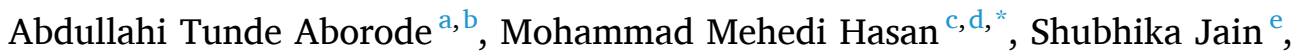 \\ Melody Okereke ${ }^{\mathrm{f}}$, Oluwakorede Joshua Adedeji ${ }^{\mathrm{f}}$, Ayah Karra-Aly ${ }^{g}$, Ayoola S. Fasawe ${ }^{\mathrm{h}}$ \\ ${ }^{a}$ Healthy Africans Platform, Research and Development, Ibadan, Nigeria \\ ${ }^{\mathrm{b}}$ West African Institute of Public Health, Abuja, Nigeria \\ ${ }^{\mathrm{c}}$ Department of Biochemistry and Molecular Biology, Faculty of Life Science, Mawlana Bhashani Science and Technology University, Tangail, 1902, Bangladesh \\ ${ }^{\mathrm{d}}$ Division of Infectious Diseases, The Red-Green Research Centre, BICCB, Dhaka, 1215, Bangladesh \\ ${ }^{\mathrm{e}}$ Kasturba Medical College, Manipal, India \\ ${ }^{\mathrm{f}}$ Faculty of Pharmaceutical Sciences, University of Ilorin, Kwara State, Nigeria \\ ${ }^{g}$ Schulich School of Medicine and Dentistry, University of Western Ontario, London, Ontario, Canada \\ ${ }^{\mathrm{h}}$ Department of Cellular Biology and Genetics, Illinois State University, USA
}

\section{A R T I C L E I N F O}

\section{Keywords}

COVID-19

Health system

Disease surveillance

Africa

\begin{abstract}
A B S T R A C T
Infectious disease outbreaks have long posed a public health threat, especially in Africa, where the incidence of infectious outbreaks has risen exponentially. Although, Africa has witnessed several outbreaks of emerging and re-emerging infectious diseases such as Ebola virus disease and other epidemic-prone diseases, little attention has been given towards strengthening the health surveillance systems. However, the recent COVID-19 pandemic has uncovered the region's already due to inefficient and ineffective health surveillance systems. However, the impact posed by the COVID-19 pandemic on health systems in the region has been catastrophic, it has also stressed the importance of rethinking and focusing on lessons learned during the COVID-19 pandemic. In this paper, we examine how Africa's poor disease surveillance systems affected the responses and strategies aimed at COVID-19 containment. To ensure early disease outbreak identification and prompt public health interventions in Africa, the current disease surveillance and response mechanisms must be strengthened.
\end{abstract}

\section{Introduction}

Infectious diseases continue to be the major public health problem in Africa. ${ }^{1}$ A working disease surveillance system is essential for setting priorities, preparing, mobilizing, and allocating resources, predicting and detecting disease outbreaks, and monitoring and evaluating intervention programs. ${ }^{1}$ In the case of an unprecedented public health threat, national and regional surveillance systems are often put to the test. In Africa, the majority of already-existing disease surveillance systems are not effectively measuring the health impact of major disease outbreaks, also not adequately evaluating current disease control programs or detecting outbreaks for timely public health intervention. ${ }^{1}$ For instance, we can recall the Ebola virus disease (EVD) outbreak in West Africa that occurred between 2013 and 2016. ${ }^{2}$ The EVD outbreak went unnoticed for months due to poor surveillance systems, which largely resulted in late detection and response. ${ }^{2}$ This is consistent with recent studies that identified poor epidemiologic data collection and implementation as a challenge to addressing potential health threats at the national levels in Africa. ${ }^{3-5}$

In 2020, Africa's total recorded population was estimated to be over 1.34 billion, accounting for $16 \%$ of the global population. ${ }^{6}$ Over the last 20 years, the region has made progress in reducing premature death and disability due to several communicable, neonatal, nutritional, and maternal causes, particularly diarrheal illnesses and lower respiratory infections. ${ }^{7}$ Deaths from measles and tetanus have substantially declined since 1990 even though there are cases reported lately. ${ }^{7,8}$ Malaria and HIV/AIDS caused more deaths in 2010 than in 1990, however both diseases peaked in most countries between 2000 and $2005 .{ }^{9}$ For years, the presence of various endemic infectious diseases has contributed to the overburdening of African countries' health systems. ${ }^{10}$

\footnotetext{
* Corresponding author. Department of Biochemistry and Molecular Biology, Faculty of Life Science, Mawlana Bhashani Science and Technology University, Tangail, 1902, Bangladesh.

E-mail address: mehedi.bmb.mbstu@gmail.com (M.M. Hasan).
} 
The emergence of COVID-19 in Africa has made it more difficult to get health services, as well as hampered treatment, testing, immunization, and surveillance efforts for other infectious illnesses throughout Africa. ${ }^{8,10-12}$ Data on infectious diseases in most African countries is poor and ambiguous as the focus switches to COVID-19 care. For example, Egypt has devised several measures that was put in place during COVID-19, which includes improving their surveillance system to track down diseases and contact tracing, improving healthcare management, and establishing a national Egyptian surveillance system to understand the current stage of the pandemic in Egypt. ${ }^{13}$ During the COVID-19 response, dense countries in Africa reinvigorate their disease monitoring systems by collaborating regionally to curb down the infection spread, assist in emergency response and management, as Ethiopia has done with its neighboring countries Kenya and Somalia. ${ }^{14}$ However, Congo has been lacking sufficient interventions regarding disease surveillance system during COVID-19 response which reflect on its deficient healthcare system and its failure in assessing lessons learned from the previous Ebola outbreak. ${ }^{15}$

Several challenges have been identified to be responsible for the relatively poor surveillance of disease outbreaks in Africa. If the region is to achieve substantial progress in the early detection and control of disease outbreaks, efforts and responses to resolve these challenges must be intensified.

\section{Reasons for poor disease surveillance in Africa}

Implementing efficient and effective infectious disease surveillance programs is key to quality public health system and in reducing mortality and morbidity in Africa. Public health surveillance facilitates accessibility of data and information and reduces the burden and spread of adverse healthcare events. In turn, this enables fast-moving public health response strategies, it allows for effective monitoring and evaluation of proposed interventions, easy identification of new and emerging diseases, and provides health security and stability for the population in Africa. ${ }^{16}$

Certain factors contribute to low disease surveillance in Africa, including ${ }^{7}$ :

(1) Inadequate involvement and contribution of resources from stakeholders, that can help strengthen the surveillance system in Africa,

(2) Inadequate utilization of the existing surveillance infrastructure to promote the public health,

(3) Lack of efforts in the development of strategies aimed at prioritizing eradication of certain endemic infectious diseases,

(4) Unfavorable legislation and regulations regarding the implementation of surveillance systems,

(5) The dearth of knowledge amongst policy makers on the potential of the impact and influence that surveillance has on public health is another contributory cause of poor disease surveillance systems in Africa.

Another underlying factor that explains the weak disease surveillance programs in Africa include the lack of properly linked electronic health records (EHRs) with data management and communication systems between primary, secondary and tertiary care hospitals. ${ }^{17}$ Therefore, this hinders the possibility of using the data from EHRs, which appears to be a promising newer source of data for public health surveillance and for assessing the prevalence of disease or behavioral risk factors in the population-seeking healthcare. The absence of a national program for monitoring infection control and prevention activities in healthcare settings manned with dedicated experts is one of the major problems faced by most African countries.

\section{How does poor surveillance system affect covid-19 response in Africa?}

Surveillance involves continuous vigilance for health occurrences and related events in order to ensure quick response. ${ }^{18}$ Early screening resulting from proper surveillance helps achieve the primary target of preventing the spread of COVID-19. Nigeria, for example, with a population of over 200 million, requires crucial testing for quick identification of people at risk of the virus. Due to low laboratory capacity, only $1,977,479$ samples in Nigeria (less than $1 \%$ of the population) were tested at the time of this research. ${ }^{19}$

A low surveillance system impairs COVID-19 pandemic preparedness, which limits testing capacity in Africa. A weak surveillance system also inhibits rapid detection of cases in countries where the virus is not fully circulating yet. ${ }^{20}$ Low-income countries cannot afford comprehensive routine surveillance, hence limiting testing of all suspected cases. $^{20}$

Case-based routine surveillance, aggregate routine surveillance, active surveillance and Sentinel surveillance are examples of the various forms of surveillance required for effective control of the pandemic. ${ }^{20}$ However, as a result of low engagement and actions from different stakeholders in increasing the performance strength of surveillance, COVID-19 cases may have been under-reported in Africa. ${ }^{21}$ It is thus important to ramp up laboratory and diagnostic capacity in an effective and continuous structure across countries in Africa for prompt detection, and accurate predictions.

\section{Consequences}

The consequences of inefficient and ineffective surveillance strategies in Africa have led to suboptimal reporting and monitoring of public health diseases, which gives a false sense of decrease in incidences rates of prevalent diseases, ultimately affecting policy-making and eradication strategies. Additionally, inadequate understanding of the health problems in terms of aetiology, mode of transmission, and mechanism of infection, has resulted in difficulty reducing the impact of existing health issues in Africa. Low information-based activity (collection of data, analysis and interpretation of large volume of data) from healthcare centers has led to low quality delivery of healthcare services in Africa. It has also affected morbidity and mortality rates, along with relevant general data on the leading infections in African countries.

The success of any health initiative is jeopardized because of low disease surveillance in Africa. This has led to disorganized healthcare sectors with poor infrastructure, low knowledge trends and low-quality healthcare delivery, which indicate low sustainability. Moreover, it has also affected the accurate assessment of the health systems as well as health promotion programs, leading to unproductive resource allocation by program investors.

\section{Efforts}

African centers for disease control and prevention (CDC), given collapsing surveillance amidst COVID-19 response, took an initiative to strengthen the regional disease surveillance system and integrated emergency response capabilities. This initiative was taken with the idea of effectively identifying outbreaks at the regional level before they become a disease of public health concern throughout the continent and in the neighboring regions. Through the Regional Integrated Surveillance and Laboratory Network (RISLNET), the maximization of available resources with collaborative efforts of national public health institutions, academic institutions, laboratories, centers of excellence, non-governmental and civil society organizations, and veterinary services was done, where issues like pandemic preparedness and response challenges at local and regional levels were discussed and addressed. ${ }^{22}$ This plan has successfully been implemented in central Africa and eastern Africa. Equipped laboratories, trained personnel and a 
comprehensive network of identifying pathogenic transmission and containment were successful with cross-collaboration with the neighboring regions. However, retention is as important as initiation; this plan needs continual evaluation and up-gradation through short and long-term investments in the infrastructure in order to be effective in the ongoing pandemic, and in preventing future outbreaks.

\section{Recommendation}

Over a decade, approximately 140 disease outbreaks with various endemic infectious diseases have been reported in the African continent. ${ }^{23}$ Prevention and control of these diseases have been hampered by a weak disease surveillance system. Weak infrastructure, sparse resources and lack of national disease control and preparedness programs have burdened an already debilitated healthcare system in Africa. Thus, implementing improved disease surveillance programs is imperative in preventing further deterioration of Africa's healthcare system. One such advancement seen in high-income countries is genomic informed pathogen surveillance. ${ }^{24}$ With increasing incidences of emerging and reemerging infectious diseases, antimicrobial resistance and the latest outbreaks introducing such technique at an affordable expense in Africa becomes a necessity. This system not only is an outbreak detector, but also has a wider horizon of potential to transform the public health status of Africa. With advancement, this has been made to trace the transmission network, provide investigatory, diagnostic and therapeutic benefits, vaccine development and finally, enabling proper assessment of the effectiveness of proposed public health interventions.

\section{Conclusion}

Africa is a continent with an evolving disease profile and a weak healthcare system with fewer healthcare facilities, debilitated infrastructure, and lack of resources. Its existing resources can be utilized effectively and strategically only with the existence of a vigilant surveillance system. Efforts must be made in order to optimally, and timely recognize public health threats. This can be achieved through proper, effective, and sustainable surveillance systems.

\section{Funding}

No funding from any institution or department.

\section{Authorship contributions}

Conceptualization: A.T.A. and M.M.H. Writing - Original Draft Preparation: A.T.A.; M.M.H.; S.J.; M.O.; O.J.A; A.K; A.S.F. Review \& Editing: A.T.A.; M.M.H.; A.K; S.J. All authors have read and agreed to the submitted version of the manuscript.

\section{Declaration of competing interest}

The authors declare no conflicts of interest.

\section{Acknowledgement}

None.

\section{References}

1 World Health Organization- African Regional Office. Integrated disease surveillance in the African region. A regional strategy for communicable diseases 1999-2003. htt ps://www.afro.who.int/sites/default/files/2017-06/ids-strat-99-03.pdf. Accessed May 13, 2021.

2 Bell Beth P, Damon Inger K, Jernigan Daniel B, et al. Overview, control strategies, and lessons learned in the CDC response to the 2014-2016 Ebola epidemic. MMWR Suppl. 2016;65(Suppl-3):4-11. https://doi.org/10.15585/mmwr.su6503a2external icon.

3 Davies J, Abimiku A, Alobo M, et al. Sustainable clinical laboratory capacity for health in Africa. Lancet Glob Heal. 2017;5(3):e248-e249. https://doi.org/10.1016/ S2214-109X(17)30024-4.

4 Newman MJ, Frimpong E, Donkor ES, Opintan JA, Asamoah-Adu A. Resistance to antimicrobial drugs in Ghana. Infect Drug Resist. 2011;4(1):215-220. https://doi.org/ 10.2147/IDR.S21769.

5 The Lancet Global Health. Global health security: how can laboratories help? Lancet Glob Heal. 2017;5(2):e115. https://doi.org/10.1016/S2214-109X(17)30009-8.

6 Statistics Times. Africa Population 2020; 2020. https://statisticstimes.com/demog raphics/africa-population.php. Accessed July 19, 2021.

7 The Africa Report. Africa Needs More Health Data to Improve Response to Health Crises; 2021. https://www.theafricareport.com/25951/lack-of-statistical-capacity-meansafrica-risks-shooting-in-the-dark-on-coronavirus/. Accessed July 19, 2021.

8 Mohan A, Temitope RA, Cavdaroğlu S, et al. Measles returns to the Democratic Republic of Congo: a new predicament amid the COVID-19 crisis. J Med Virol. June 2021. https://doi.org/10.1002/JMV.27137.

9 The World Bank. The global burden of disease: main findings for sub-saharan Africa. https://www.worldbank.org/en/region/afr/publication/global-burden-of-disease-fi ndings-for-sub-saharan-africa. Accessed July 19, 2021.

10 Uwishema O, Adanur I, Babatunde AO, et al. Viral infections amidst COVID-19 in Africa: implications and recommendations. J Med Virol. July 2021:27211. https:// doi.org/10.1002/JMV.27211.

11 Çavdaroğlu S, Hasan MM, Mohan A, et al. The spread of Yellow fever amidst the COVID-19 pandemic in Africa and the ongoing efforts to mitigate it. $J$ Med Virol. 2021;93(9):5223-5225. https://doi.org/10.1002/JMV.27027.

12 Hasan MM, dos Santos Costa AC, Xenophontos E, et al. Lassa fever and COVID-19 in Africa: a double crisis on the fragile health system. J Med Virol. July 2021:27169. https://doi.org/10.1002/JMV.27169.

13 Aes H, Sa Ak RK, et al. The impact of implementing the Egypt pandemic preparedness plan for acute respiratory infections in combating the early stage of the COVID-19 pandemic, february-july 2020: viewpoint. JMIR public Heal Surveill. 2021; 7(5). https://doi.org/10.2196/27412.

14 Disease ReliefWeb. Surveillance, emergency preparedness and response in eastern and southern Africa - world. https://reliefweb.int/report/world/disease-surveillan ce-emergency-preparedness-and-response-eastern-and-southern-africa; 2021. Accessed July 19, 2021

15 Lm M, S H, Y M, et al. Recommendations for the COVID-19 response at the national level based on lessons learned from the Ebola virus disease outbreak in the democratic republic of the Congo. Am J Trop Med Hyg. 2020;103(1):12-17. https:// doi.org/10.4269/AJTMH.20-0256.

16 Mwabukusi M, Karimuribo ED, Rweyemamu MM, Beda E. Mobile technologies for disease surveillance in humans and animals. Onderstepoort $J$ Vet Res. 2014;81(2). https://doi.org/10.4102/ojvr.v81i2.737.

17 Mahomed S, Mahomed O, Sturm AW, Knight S, Moodley P. Challenges with surveillance of healthcare-associated infections in intensive care units in South Africa. Crit Care Res Pract. 2017;2017. https://doi.org/10.1155/2017/7296317.

18 Ogboghodo EO, Osaigbovo II , Obarisiagbon OO, et al. Facility-based surveillance activities for COVID-19 infection and outcomes among healthcare workers in a Nigerian Tertiary Hospital. Am J Trop Med Hyg. 2021;104(3):1034-1040. https:// doi.org/10.4269/ajtmh.20-1402.

19 Nigeria Centre for Disease Control. Covid-19 Nigeria. https://covid19.ncdc.gov.ng/. Accessed May 13, 2021.

20 Ibrahim NK. Epidemiologic surveillance for controlling Covid-19 pandemic: types, challenges and implications. J Infect Public Health. 2020;13(11):1630-1638. https:// doi.org/10.1016/j.jiph.2020.07.019.

21 Ohia C, Bakarey AS, Ahmad T. COVID-19 and Nigeria: putting the realities in context. Int J Infect Dis. 2020;95:279-281. https://doi.org/10.1016/j. ijid.2020.04.062.

22 Strengthening the role of regional public health institutions to improve cross-border disease surveillance and response in Eastern and Southern Africa | PreventionWeb. net. https://www.preventionweb.net/news/view/76717. Accessed May 13, 2021.

23 Emergency Operations: Annual Report. Saving Lives and Reducing Suffering: WHO's Work in Emergency Response Operations in the WHO African Region in; 2018. https://reliefw eb.int/sites/reliefweb.int/files/resources/WHO-AF-WHE-EMO-01-2020.pdf.

24 Implementing pathogen genomics: a case study - GOV.UK. https://www.gov.uk/ government/publications/implementing-pathogen-genomics-a-case-study. Accessed May 13, 2021. 